\section{Markierung pathologischer Analysenergebnisse}

O. Colhoun

Institut für Laboratoriumsmedizin, Klinikum Frankfurt

Höchst, Frankfurt am Main, Deutschland

\section{Englischer Begriff marking}

Definition Kennzeichnung eines Messwertes (s. $>$ Messwert) in der Labor-EDV.
Beschreibung Die jeweilige Kennzeichnung weist auf Über- oder Unterschreitung des Referenzbereiches (in mehreren möglichen Ausprägungen von leicht bis extrem pathologisch; s. - Referenzbereich, biologischer, R Referenzbereich, dosisbezogener) oder präanalytische $>$ Einflussgrößen (Hämolyse, Hyperbilirubinämie etc.) hin, die bei der Beurteilung des Messwertes mit einbezogen werden müssen. Die jeweiligen Beurteilungsgrenzen sind in den $>$ Stammdaten der $>$ Labor-EDV für die Messgröße hinterlegt. 